\title{
28 Research Square \\ Productivity Impact of Climate Change on Primary Export Commodity in Africa
}

Berihu Assefa Gebrehiwot ( $\nabla$ berihuua86@gmail.com )

Ethiopian Development Research Institute https://orcid.org/0000-0002-1999-045X

Alebel B. Weldesilassie

Ethiopian Development Research Institute

\section{Research Article}

Keywords: productivity, climate change, Ethiopia, export

Posted Date: November 17th, 2021

DOI: https://doi.org/10.21203/rs.3.rs-1047410/v1

License: (c) (i) This work is licensed under a Creative Commons Attribution 4.0 International License. Read Full License 


\section{Abstract}

Using a large household survey dataset and climate data, we estimated and analyzed the productivity impact of climate change on two strategic export commodities, cotton, and sugarcane, in Ethiopia. The productivity impact revealed that it is likely that climate change will significantly reduce the productivity of sugarcane and cotton. In addition, net revenue from sugarcane and cotton will also be reduced due to an increase in annual and seasonal temperature as well as changes in mean annual and seasonal rainfall. We have presented results for various climate scenarios and seasons. We also found that nonclimate drivers of vulnerability such as gender, education, access to extension services and credit, technology use, access to land and non - farm income, and natural assets will exacerbate the negative impacts of climate change.

\section{Introduction}

Global temperatures are likely to increase by at least $2^{\circ} \mathrm{C}$ compared with pre-industrial levels by the end of this century. Besides, the intensity and frequency of extreme climatic conditions are expected to increase and the predictability of normal rainy seasons to decrease. As a result, poor countries with large rural economies that depend on agricultural exports may be negatively affected since agricultural export earnings may be jeopardized unless alternatives are sought for building the resilience of the sector to the anticipated climate change impacts. Not only that their export earnings is under risk but also that climate change poses risk to actors along the value chain of the agricultural commodities though the impact on these actors varies with the extent of exposure as well as their sensitivity to the impact.

The impact of climate change on agricultural export commodity earnings and other actors is reflected through its impact on its productivity. There is a general agreement that climate change may lead to significant reductions in agricultural productivity in developing countries. This productivity impact may be due to change in temperature and precipitation, change in soil moisture and soil fertility, changes in the length of growing season as well as change in the probability of occurrences of extreme events such as drought and flood. The reduction in productivity will likely translate to reduced income and availability of food at the household level and thereby affect the welfare of the actors. Their welfare is also affected through its direct effect on their livelihood strategy as well as on assets and infrastructures. In addition to its direct effect, the increase in climate variability will likely make the actors vulnerable, which can also exacerbate the incident of deterioration of their welfare. Overall, climate change may affect household welfare mainly through its impact on productivity though it also affects it through its effect on asset, access to basic services as well as infrastructure. However, the impact depends on the level of vulnerability that determines their adaptive capacity. Among the different actors, those who directly depend on the production of the agricultural commodity for their income are more vulnerable to climate change impact. Empirical evidences on agricultural productivity and welfare of households revealed that there is a considerable heterogeneity in the impact due to variations in geographical location, household specific characteristics as well as other specific features of households in their effectiveness of risk management. 
This study focuses on the productivity impact of climate change in sugarcane and cotton producing regions of Ethiopia. Cotton and sugarcane are considered major industrial inputs for textile and sugar industries, which are strategic export commodities in the industrial development strategy of Ethiopia (MoFED, 2010). Our goal in this paper is to analyze the productivity impacts of climate change. To this end we have employed household-level data collected from sugarcane and cotton producing areas in Ethiopia, and climate data (rainfall and temperature) was obtained from the Ethiopian Meteorology Agency for the period 1961-2014.

The rest of the paper is organized as follows. Section two provides review of previous empirical evidences on the impact of climate change on productivity. The evidence is reviewed with a focus on how climate change impacts on agricultural export commodities translate into the impact on household productivity. Section three presents the methodology used to estimate the productivity impact in the sugarcane and cotton producing regions of Ethiopia. It discusses the data and the model used to estimate the impact. While the results of the model and the findings will be discussed in section four, section five concludes the paper.

\section{Previous Evidences On The Productivity Impact Of Climate Change}

This section reviews previous empirical evidences on the productivity impact of climate change. A brief summary of the channels through which climate change manifests its effect on productivity is presented. This will be followed by a brief summary of the disproportionate and heterogeneous nature of its impact. The sources of this heterogeneity and the different mechanisms that are included in the models used to estimate the impact and are found to have significant impact in minimizing the impact are discussed in sub sections three and four, respectively.

\subsection{Channels of climate change impact}

Climate change manifests itself in several forms. Among these are the rise in sea levels causing coastal flooding, higher temperature, reduction in precipitation and erratic and extreme climate events (IPCC, 2013). All of these have implications for agricultural productivity and hence the welfare of households (McGuigan et al., 2002). Climate change affects agricultural productivity through various channels. The rise in temperature along with the reduction in rainfall reduces agricultural productivity if both are beyond the threshold that is suitable for crop production (Cabral et al., 2007; McGuigan et al., 2002; Skoufias, 2014). Climate change could also result in a change in the length of seasons. In places where traditional agriculture dominates, the change in the length of the seasons makes it difficult to conduct the crop production process at the regular time unless some sort of adaptation mechanism is adopted (Cabral et al., 2007 and McGuigan et al., 2002). Climate change also increases the probability of extreme weather conditions such as drought and heavy precipitation (IPCC, 2013 and Skoufias, 2012). Such events could obliterate agricultural produce and household's productive assets. This would have a negative effect on both current and future food security status of households respectively (Cabral et al., 2007 and McGuigan et al., 2002). Lastly, the level of soil fertility is altered due to climate change (McGuigan et al., 2002). All of 
these factors work jointly to reduce agricultural productivity and, therefore, weaken the status of food security.

The reduction in agricultural productivity due to climate change has a strong welfare implication for many of the countries with majority of their population relying on agriculture for livelihood. The loss of agricultural productivity affects the income and consumption of households. It could either push or keep households below the poverty line. The ability of net consumers to purchase consumer products could be constrained due to the reduction in their income. Net producers could also face a decline in their consumption due to smaller crop yield (Karfakis et al., 2012).

Skoufias (2012) identifies three ways through which climate change could affect households. The first is the deterioration of households' asset base. The advent of a climate change event would force households to sell their assets to mitigate the impact of these extreme climatic conditions. The fact that extreme climate events are of covariate nature rather than idiosyncratic make it difficult to access credit markets to mitigate this risk (McGuigan et al., 2002). This problem is further accentuated by the lack of efficient capital and insurance markets in developing countries (IPCC, 2014 and Skoufias, 2012). Furthermore, if households sell productive assets, the extreme climatic event may have a lasting impact by limiting the households' future capacity to produce.

Secondly, there are various ways through which climate change may affect the health of household members. The increase in temperature which is a typical manifestation of climate change allows more disease vectors to survive (Majule and Mary, 2008; McGuigan et al., 2002; Skoufias, 2014). The reduction in water resources aggravated by the population pressure especially in urban areas prevents a hygienic lifestyle thereby worsening health (McGuigan et al., 2002 and IPCC, 2014). Extreme weather events also expose people to injuries which may have both short term and long term implication on their health (IPCC, 2014). In addition, the reduction in real income due to food price rise for net consumers and the decrease in crop production for net producers could have an impact on the nutrition of household members which in turn affects their health (Karfakis et al., 2012).

The third impact Skoufias (2012) identified is the reduction in access to water and infrastructure. The gradual decline in precipitation especially in tropical areas creates a constraint in water supply. Furthermore, extreme climatic events could destroy the infrastructure already in place. The decrease of agricultural productivity manifested in the reduction of crop yield not only creates loss of farm income but also has impact on the labor allocation of the households. The loss of income may force households to allocate their labor to non-farm income sources and may even result in migration (Gemenne, 2010). Female members of the households that normally engage in household activities may also be forced to leave the household to earn income (Karfakis et al., 2012). This leaves children without care which thereby affects their wellbeing both in terms of nutrition and education. Children may also be forced to work outside the household which comes at the expense of their education (McGuigan et al., 2002).

\subsection{The disproportionate effect of climate change}


Several studies have pointed out that there will be gain in agricultural productivity in higher latitudes and loss in tropical areas. The reason behind this gain is the existence of a threshold beyond which temperature starts contributing negatively (Cline, 2007). If temperature rises above its current average in tropical areas, it will bring about drought, pests and diseases thereby reducing agricultural productivity (Cabral, 2007). Food production would, therefore, decline. Moreover, precipitation has been rising in the temperate areas (IPCC, 2013). This further contributes to the improvement in agricultural productivity in higher latitudes.

The overall food supply at the international level may increase. However, the reduction in domestic supply of food is likely to create food price spikes in developing countries. The shortage of food supply could be filled through imports. Various groups are affected differently through these price hikes. One of the main explanations behind this is the net production and consumption position of households (Skoufias, 2014). Net producers are likely to benefit from the price rise in contrast to net consumers who would lose since they would need to purchase food to meet their consumption needs. The overall effect will depend on the net position of the households (Deaton, 1989). The net position in turn is determined by factors such as level of urbanization and access to land and technology. Climate change has a regressive impact on the poor - the poor are more likely to be affected than the rich. Moreover, the urban poor (wage laborers) are more likely to be affected with the increasing trend in urbanization and the fact that urban workers are net consumers. Food price hikes would, therefore, affect the urban poor more than any other group (Skoufias, 2012).

An important implication of the differential impact of climate change on agricultural productivity in high latitude and low latitude areas is that it sustains and exacerbates the existing inequality between developing and developed countries (Cabral, 2007 and McGuigan, 2002). Not only are developing countries more vulnerable to the impacts of climate change as they are more dependent on economic activities whose productivities depend on weather conditions, they also lack effective financial systems that can help cope with these risks (Skoufias, 2012). This problem is further intensified by the fact that 'weather shocks' are of covariate nature which makes it difficult to mitigate even with the existence of efficient credit and insurance markets (McGuigan, 2002).

Moreover, coping and adaptation with the effects of natural hazards depends on economic resources, infrastructure and technology which are lacking in developing countries. This constrains the ability of such countries to engage in ex-ante risk management mechanism such as early warning and ex-post shock coping mechanisms such as disaster response, victim relief and assistance (Karfakis et al., 2012 and McGuigan, 2002).

The role played by high population growth and rapid urbanization, both of which characterize developing countries, in aggravating the impact of climate change in developing countries is also pertinent to the analysis (IPCC, 2000 and McGuigan, 2002). Given the fact that the urban poor are the most affected by the food price hikes resulting from reduced crop yield, the unrestrained rapid urbanization process observed in many developing countries increases the group that loses from the rise in food price, i.e., the 
net consumers (Karfakis et al., 2012). Rapid population growth also creates pressure on natural resources and leaves less food per capita.

In summary, the process of climate change not only has a negative effect on the overall wellbeing of households in developing countries, but also plays a role in increasing the inequality between developing and developed countries. This implies that the burden of climate change is born disproportionately by the poor both within and cross country settings.

\subsection{Sources of Heterogeneity of Impact}

A crucial point to note when looking into the impact of climate change on all economic units is that it is heterogeneous. It is dependent on a myriad of factors among which are wealth, location, access to infrastructure and basic services, education, net production and consumption position, gender, access to land and modern agricultural inputs (IPCC, 2014 and Skoufias, 2014). The specific agro-ecological zone an economic unit is located in determines whether it will benefit or lose from climate change (Tol, 2009). In general, there is a possibility that temperate areas may benefit from climate change in terms of agricultural productivity since the temperature change may not have reached the threshold beyond which crop yield declines (Cabral et al., 2007 and Cline, 2007). The reverse is true in tropical areas. Not only does climate change increase susceptibility to drought but also increases the exposure to pests and diseases (IPCC, 2014; McGuigan et al., 2002; Skoufias, 2014). The location of the household also affects its access to infrastructure and markets which are important factors in determining the strength of the impact of climate change on the household (Skoufias et al., 2012).

The income, asset and expenditure structure of households also affects the strength of the impact of a climate related risk. If households have enough resources to rely on at the time of such events, climate related impacts can be mitigated relatively easily (Skoufias, 2014). Moreover, rich households with larger access to land could lose due to the loss in agricultural productivity. Wage earners, on the other hand, could be insulated from this impact if they are not engaged in agricultural activities. However, the wage earners could lose due to the food price rise caused by the reduction in food supply. The overall effect hence depends on whether the loss of return from land and labor outweigh the loss of real income due to price rises for the poor (Skoufias et al., 2012).

The education level of the household may also affect the extent of the damage inflicted by climate change by increasing its ability to diversify and come up with adaptation mechanisms to mitigate the climate related risk (IPCC, 2014). Greater human capital endowment of the household could also contribute the household by making it less dependent on agriculture for income. The argument of Skoufias et al. (2012) in determining the overall effect would apply for education as well.

The gender of the household head and the gender composition of the households also has implication on the size of the impact of the climate change. Karfakis et al. (2012) and Barrientos and Khanji (2002) argue that female headed households are more vulnerable to the impacts of climate change in comparison to their male counterparts because they have limited access to land and financial services 
which are important resources to mitigate the negative effects of climate change. Hence, female headed households are more likely to be affected by climate change than male headed households. Female members of the household will also be forced to leave the household to earn income mostly under dire working conditions as a result of reduction in income or agricultural produce due to climate change (Barrientos and Khanji, 2002). This implies that labor is reallocated from reproductive to productive labor. This reallocation deprives children of child care and weakens their status of nutrition and educational performance. This slows down the process of human capital accumulation of the households.

Households' access to modern agricultural inputs also affects how well households can respond to climate change. The use of modern agricultural inputs helps households to circumvent the negative impacts of higher temperature and limited precipitation (IPCC, 2014). This is one of the ex-ante risk management mechanisms adopted by crop producers (Karfakis et al., 2012). It is also part of the recommended climate change adaptation mechanisms (IPCC, 2014). This argument is supported by Amaliah et al. (2012), which has shown that increased investment on agricultural research and development significantly reduces the impact of climate change on household consumption which is an important indicator of welfare.

To conclude, at the household and community levels, these factors result in a variation in the impact of climate change on households. Hence, it is crucial to take them into account in trying to explain the heterogeneity in the effects of climate change on agricultural production and household welfare.

\subsection{Adaptation as means of reducing the impact}

The extent of the effect of climate change on poverty depends on the effectiveness of the adaptation strategy adopted by households, if at all they have an adaptation strategy. If adaptation strategies are carefully planned, they can significantly reduce the negative impacts of climate change (Skoufias et al., 2011). Adaptation strategies must particularly target those that are vulnerable to this change given the resource constraints. Hence, it is necessary to equip this group with the necessary tools to mitigate the impact (Kyotalimye et al., 2010). Skoufias (2012) identifies four important factors that determine households' ability to adapt to climate change events. Among these are autonomous adaptation strategies which are dependent on the ability to shift from the agricultural sector to a non-agricultural sector. The faster one can shift between the two, the lesser the damage inflicted will be.

Adaptation mechanisms can also be induced by governments through policy and direct intervention. Access to these interventions affects the ability of the household to mitigate climate related risks. Conditional cash transfer programs and safety net programs are examples of such intervention. Governments also intervene to improve households' access to credit and insurance so that the climate related risks are effectively mitigated.

The third important factor that determines the ability of households to adapt to climate change events is the relative productive endowment of the households. The nature of land held by households, for example, whether or not it is irrigated, affects the ability of the household to adapt to these changes. 
Moreover, the skill composition of the households' labor also has an implication on its adaptation capacity.

Lastly, as has been discussed in the earlier sections of this review, the net consumption and production position of the household determines its ability to adapt to climate change and which adaptation mechanism fits the household.

A crucial factor in ensuring the success of adaption strategies is the dissemination of information about climate related risks in the future. This allows one to take into account the expected patterns in temperature and precipitation and, hence, its resulting impact on agricultural productivity in designing adaptation strategies. This adds to the strength of the adaptation strategies in mitigating climate related risks (Skoufias et al., 2011).

There are various forms of adaptation strategies adopted by households to mitigate climate related risks particularly in the agriculture sector. Households adjust their consumption and production patterns in response to changing climate which affects their agricultural productivity (Skoufias et al., 2011). One form of response is changing their cropping pattern to deal with the timing of the seasons that is altered due to global climate change (Majule and Mary, 2008). Another form of adjustment in production patterns comes through the use of improved inputs and better production technology in agriculture. Migration is also used as an adaptation strategy to mitigate the risks of climate change (Gemenne, 2010).

At policy level, there are initiatives to establish governance systems for adaptation in many African countries. The efforts are exerted in different dimensions such as disaster risk management, adjustment in technologies and infrastructure, ecosystem-based approach and public health measures and livelihoods diversification. Although these initiatives have contributed to the alleviation of vulnerability, they are criticized for lacking coordination in deploying them (IPCC, 2014). Among the policy measures that can be adopted to help households and communities to adapt to climate change are well-targeted safety net programs that can be scaled up (Skoufias, 2012 and Skoufias et al. 2011). Given the lack of access to capital and insurance markets in developing counties, improving the access to such markets could also improve the capacity of the poor to adapt to climate change. Any climate related risk could be circumvented through credit or insurance without the need to sell productive assets or wipe out savings (McGuigan, 2002).

In terms of the management of natural resources, the improvement in the governance of common-pool natural resources and raising the investment on irrigation and improved water management could help maintain or increase agricultural productivity by dealing with events of extreme precipitation (Skoufias et al., 2011). However, it is argued that solely focusing on water management practices in dealing with the impacts of climate change without the consideration of social, institutional and ecosystem based measures limits the capacity of the measures to effectively tackle climate change events (IPCC, 2014). 
Expansion of access to international markets is also one form of an adaptation strategy. Regional and country specific climate shocks are likely to cause food price hikes. In this case, ensuring trade openness could insulate net consumers from the impact by alleviating the increase in food prices. Hence, an intervention through the liberalization of trade could contribute to the mitigation of the impact of climate change (Cirera et al., 2002 and Skoufias et al.,2011). Another crucial factor to ensure the mitigation of the impact of climate change is occupational mobility. With the ability to shift between occupations, it is possible to escape the impact of climate change by switching jobs (IPCC, 2014 and Skoufias et al., 2011). This is similar to livelihood diversification which is also one sort of an adaptation strategy. Households diversify their risk by sourcing their income from different activities. This way, they can rely on an alternative source if one of their income sources is affected by a climate change event (IPCC, 2014).

Overall, adaptation strategies are necessary to reduce the impact of climate change on poor households. These strategies come both in terms of changes in consumption and production patterns, direct intervention by governments and policy induced. Although the importance of these strategies to protect the vulnerable cannot be debated, the success of such adaptation strategies, however, depends on the inclusion of social, institutional and ecosystem measures in designing the adaptation strategies.

\subsection{Methodological review}

A review of the literature on the welfare impact of climate change revealed that there are different approaches used to estimate the impact. These approaches range from use of economy-wide growth model to household model. One feature of the former model is that, using aggregated data, it incorporates consistent climate-change scenarios to show how climate change might affect the path of poverty. For instance, using aggregated data, one can estimate the percentage change in output due to a change in climate. The different studies that use such approach differ in their estimation of the impact depending on the type of information they use. Zhai et al (2009) used comparable general equilibrium (CGE) model in order to examine the impact of climate change on agriculture sector of China in 2080. Similarly, using a Social Accounting Matrix, a CGE model is used to estimate the macroeconomic effects of climate change in Uganda (Matovu and Buyinza, 2010). The authors argued that use of such model has a number of strengths. Firstly, the model simulates the functioning of the economy as a whole and track how changes in economic conditions are transmitted through price and quantity adjustments on a range of markets. Secondly, the structural nature of the CGE model allows us to analyse separately the impacts of multiple climate changes. Thirdly, since the basis of the CGE model is a Social Accounting Matrix, we are able to discern the effects of the changes in economic conditions on individual sectors of the economy. Fourthly, the link of the model to household survey data enables an assessment of the impacts on the welfare of households, which is particularly interesting since this is where the most important policy implications are likely to be found. Finally, the recursive dynamic nature of our model implies that the behaviour of its agents is based on adaptive expectations when faced with difficult circumstances, rather than on the forward looking expectations that underlie inter-temporal optimization models. A simulation model is also used in estimating the impact of climate change. For instance, Cerri et al (2007) used simulation model for Central South region of Brazil up to 2050. They revealed that $30 \mathrm{C}$ to 
$50 \mathrm{C}$ increase in temperature and $11 \%$ increase in precipitation would cause a decrease in the productivity of wheat to the level equal to one million ton by weight. Ayinde, et al. (2010) using time series data empirically analyzes trend climate change and agricultural production in Nigeria. Their Granger causality analysis indicates that there is a relationship between changes in rainfall and agricultural production in Nigeria. Deschênes and Greenstone (2007) propose a fixed-effect model that exploits the presumably year-to-year variation in temperature and precipitation to estimate the impacts of climate change on agricultural profits and yields. More specifically, the authors use a county-level panel data to estimate the effect of weather on US agricultural profits, conditional on county and state by year fixed effects. Hertel, Burke, and Lobell (2010) analyzed the impacts of climate change through a more careful modelling of the channels and heterogeneity of impacts in the context of economic growth. They use disaggregated data on household economic activity (stratified by primary source of income) within 15 developing countries and a general equilibrium global trade model (the Global Trade Analysis Project, or GTAP) to explore how changes in agricultural productivity will affect poverty in poor countries. Although their model allows only limited heterogeneity, a key feature is that it allows different types of households to be affected differently by the prices of agricultural goods. The authors use three scenarios of how climate change affects agricultural productivity (low, medium, or high productivity) to evaluate the resulting changes by 2030 in global commodity prices, national economic welfare, and poverty headcount rate.

These studies are informative as they provide the magnitude of the impact. However, general equilibrium models have tradeoffs between the tractability of the general equilibrium effects and the heterogeneity incorporated into the model. In addition, studies based on aggregated data may not provide clear channels through which climate change translates its impact on the welfare of households. In addressing such shortfalls, studies used a microeconomic approach, which helps to shed light on the channels through which climate change can affect household welfare. A production function approach, also called 'agronomic model', is one such approach that was also used in some studies to estimate the welfare impact of climate change. For instance, Decker et al. (1986), Adams (1989), among others adopted this approach. This approach takes an underlying production function and varies the relevant environmental input variables to estimate the impact of these inputs on production of different crops. Ricardian model is another method commonly used in estimating the impact of climate change. The model first captures the type of crop a farmer will select and then examines the conditional net revenue of that crop.

Kurukulasuriya and Mendelsohn (2008) examine the impact of climate change on primary crops grown in Africa. Using sample of 5,000 farmers, they find that farmers use crop switching as a strategy for adapting to climate change using a 'structural Ricardian model'. The main conclusion from this study is that farmers shift the crops they plant to match the climate they face. Studies that fail to account for crop switching will overestimate the damages from climate change and underestimate the benefits. The same approach is also used by Temesgen et al. (2009). Their study empirically analysed the farmer adaption techniques to varying climate change in Ethiopia using the Ricardian approach with household level data from different agro-ecological zones of the country. In their empirical analysis, net crop revenue per hectare was regressed on climate, household and soil variables. The findings from their study show that these variables have a significant impact on the net crop revenue per hectare of farmers under Ethiopian 
conditions. Baez and Mason (2008) and World Bank (2012) provided a thorough review of the Literature on the welfare impact of climate change. Though numerous studies have examined the welfare impacts of climate change, only few studies used actual weather data to analyse the general relationship between weather and the level of welfare. After a detailed review of the different literatures, this study used a microeconomic approach in which observed and projected climate variables are modelled along with non-climate drivers of vulnerability to estimate the productivity and welfare impact of climate change. This approach is discussed in the following section.

\section{Methodology}

This section presents the approaches used to estimate the productivity and welfare impact of climate change including the type of data, econometric model as well as how we measure the key variables included in the model.

\subsection{Data}

This subsection discusses the data and techniques used to match household data and climate data as well as how we measure the outcome variables including productivity and welfare. It also discusses the technique used to estimate the projected impact of climate change.

\section{a. Household data}

The study used household survey data collected in sugarcane and cotton producing areas of the country. The survey covered three regions, namely: Oromia, Amhara and Tigray. Afterwards, 9 woredas were selected based on their contribution to the country's cotton and sugarcane production. Hence, the numbers of woredas were unevenly distributed among the regions. While two woredas were selected from Tigray, four were selected from Amhara. The remaining three were from the Oromia region. Overall, the survey collected information from 1206 households in these woredas.

The household survey collected detail information from each household including basic demographic and human capital; use of technology; asset holdings and amount of income and income sources. We also collected household consumption and expenditure including food and non-food expenditure; access to infrastructure including road, market, school and health centres. We also collected production management of agricultural crops including land size owned and cultivated, number of plots, use of technology, crop output, revenue and cost of production as well as irrigation management. Information was also collected on access to institutional services such as extension services, technology supply as well as access to market and climate related information. Community level information was also collected in addition to climate related information including perception on change in temperature and rainfall[1].

\section{b. Climate data}


To capture the effects of climate change and explore the potential for climate change adaptation and resilience, rainfall and temperature data was obtained from the Ethiopian Meteorology Agency for the period 1961-2014. Daily, monthly, seasonal and annual values for rainfall and minimum and maximum temperature for the same period was obtained for meteorological sites near the survey villages. Accordingly, climate variables are computed from these time series climate data.

As climate is a long term phenomenon measured in its deviation of climate variables, we measure climate shock by constructing two dummy variables based on the degree of deviation of the rainfall and temperature for the survey year 2013 from the long term average 1961 - 2014. A rainfall shock is identified by those observations where the weather variable is more than one standard deviation away from its long run mean. An observation is identified as excess rainfall if the rainfall for 2013 is at least one standard deviation more than the average for the long term average. It is identified as shortage of rainfall if it is at least less than one standard deviation from its long term average. The same is true for the temperature.

\section{c. Matching household data and climate variables}

The household data and climate data is matched in such way that we computed a climate shock for each meteorological sites and matched the computed shock to households who are located to the nearest meteorological site. As our climate modelling activities are made based on a regional downscaling method, rather than the GCM, in estimating the future projected climate change, this matching exercise does not have any effect in demeaning the effect of climate change[2].

\subsection{Measuring outcomes}

We estimated the impact of climate change on two key outcome variables, namely, productivity and household welfare. We measure productivity using two indicators. First, we computed yield from the household data. Yield is computed for sugarcane since we have sugarcane production data from our survey. But as we do not have enough observation for cotton production during our survey production year, we calculated yield for other crops grown in cotton producing regions. Second, we also measured productivity using net crop revenue, total crop revenue minus all cost of production for sugarcane and other crops.

Household welfare is the other outcome variable, on which we estimated climate change impact. We measured welfare using three variables including household food expenditure per capita, non - food expenditure per capita and total expenditure per capita.

The impact of climate change on these two outcomes is estimated using the result of econometric model and the projected climate change result of the climate modelling study. We first estimated econometric model in which the regressand is either the productivity or welfare indicator and the regressors are climate and other variables, which are discussed in the next section. We used the result of the model to 
estimate the projected impact; in estimating the projected impact, we used the output of the climate modelling for the projected changes in rainfall and temperature. We estimated the impact for three climate scenarios including RCP2.5, RCP4.5 and RCP8.5[3] for short term (2016 - 2035), medium term (2046 - 2065) and long term Periods (2081 - 2100).

\subsection{Econometric model specification and estimation}

Different approaches have been used to estimate the impact of climate change on the welfare of households. These range from using an economy-wide growth models to a cross sectional models. The former incorporates consistent climate change scenarios to estimate and predict the impact of climate change on poverty using aggregated data while the latter approach uses a cross sectional historical data to analyse the effect of climate change on economic activities and ultimately on poverty. While most models examine the relationship between climate and economic variables, they differ in their estimates as well as in the use of welfare indicators[4].

Our study used a microeconomic approach that can provide the channels through which climate change can affect household welfare. In this respect, the study tries to single out the impact of climate change by controlling other non-climate drivers of vulnerability. We also separated the productivity and welfare impact by estimating different econometric models. Thus, the study identified variables that would enable it to effectively capture climate change. Moreover, other control variables that are pertinent to the explanation of the variation in productivity and welfare were selected. Accordingly, the following model is used to estimate the productivity and welfare impact of climate change

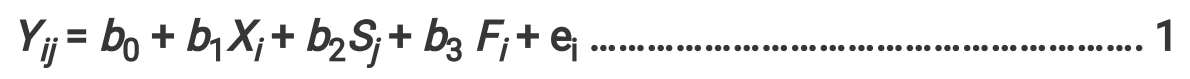

A brief discussion of the model is presented below for each of the outcome variables: productivity and welfare.

\section{a) Estimating a productivity model}

In estimating the productivity impact of climate change, the following variables are included in model (1). The study captured productivity using two variables - yield per hectare and value of output. Thus, Yij represents a vector of dependent variables (yield, value of output), Xi represents a vector of various control variables, $\mathrm{Sj}$ represents the covariate climate shocks and $\mathrm{Fi}$ is a binary variable representing households' residence (region, woreda). Other relevant variables were also included to control their effects. These include a vector of household demographic variables, a vector of variables capturing access to infrastructure and institutions, and binary variables to control location effects.

\section{Footnote:}


[1] Details about the household survey can be obtained on EDRI Research report number 17, which can be accessed at www.edri.org.et

[2] The other method was interpolation, which is a commonly used method used to account for a relative distance and direction between the metrological sites and the location of the households (Shepard, 1968).

[3] For concepts of these scenario used in this study, see the report on 'climate modelling study', which is available at www.edri.org.et. As a glimpse on these scenarios, RCP stands for "Representative Concentration Pathways". It is a set of climate scenarios constructed that contain emission, concentration and land-use trajectories. Four RCP scenarios named according to radiative forcing target level for 2100 are used. These are RCP2.6, RCP4.5, RCP6 and RCP8.5. The word "representative" signifies that each of the RCPs represents a larger set of scenarios in the literature. This implies that this set of RCPs should be compatible with the full range of emission scenarios (with and without climate policy) available in the current scientific literature. The word "concentration pathway" emphasizes that these RCPs are not the final new, fully integrated scenarios (i.e. they are not a complete package of socioeconomic, emission and climate projections), but instead are internally consistent sets of projections of the components of radiative forcing that are used for the input to climate models. The word "concentration" also emphasizes that instead of emissions, concentrations are used as the primary product of the RCPs designed as input to climate models. In the terminology of climate change policy, RCP8.5 scenario gives predictions that correspond to the business-as-usual development pathways. The RCP2.6 outputs indicate possible future temperature and rainfall patterns with climate change policy. RCP4.5 represents the middle situation.

[4] A review of the approach is given in section two. A study by the World Bank groups provided a good review of the different approaches used to estimate the poverty and welfare impact of climate change (Skoufias, Emmanuel, ed 2012)

\section{Productivity Impact Of Climate Change}

This section presents the productivity impact of climate change from the result obtained by estimating model (1) defined in section three. This section has two sub sections. The first sub section discusses the result of the model and briefly interprets its validity based on the results of the coefficients included. Two models are estimated. These are estimation results for a model that contains the inter-annual climate change effect and the seasonal climate change effect. For simplicity, the discussion is made by categorizing the variables included in the model into climate and non-climate drivers. The non-climate drivers are discussed for their implications on adaptation to minimize households' vulnerability or increase their adaptive capacity to climate change impact. This will be followed by a discussion on the model result of the climate change variables. The second sub section presents the magnitude of the impact for short term, medium term and long term periods using the three scenarios discussed in the methodological section for inter-annual and seasonal climate change.

\subsection{Econometric result}


We first discuss the results from the econometric model in which productivity indicator is modelled on climate and non-climate factors that affect productivity. As it is stated above, we used yield per hectare and net revenue per hectare as indicators of productivity. Thus, we estimated four models: Two estimations for each of the indicators with inter-annual and seasonal climate variables entered in the right side of the equation separately.

\subsubsection{Inter-annual climate change - productivity model}

The results for yield and revenue models with inter-annual climate variables are shown in Table 1. As we have described previously, in addition to climate variables, we have included non-climate change variables including access to resources, institutional services and technology use in the model. These factors are important in affecting productivity. We also included household characteristics to control individual effects. The first column of the table contains the different variables included to control their effect and single-out the effects of climate variables. Their impact on yield per hectare and revenue is shown in column two and three, respectively.

While two variables including family size and literacy rate significantly explain difference in productivity among households, in addition to these, access to resources (land size) and gender explains revenue from crop output. The positive relationship of family size could have resulted from the increased labour endowment a greater household size provides for the household. Moreover, literacy rate is also found to have a positive effect on both productivity variables. This supports the argument that better human capita endowment brings about improved agricultural productivity for the household.

Male-headed households have significantly higher revenue compared to female-headed households. This could have resulted from the limited access to improved agricultural technology, land and labour which are problems mostly faced by female-headed households.

Some of the indicators for access to basic services, agricultural technology, institutions and infrastructure were also found to have a statistically significant relationship with the indicators of productivity. Larger land size is also a significant factor for difference in revenue from crop output among households. Technology (use of fertilizer) and land suitability (measured in terms of fertility) have the expected positive sign and effect on productivity. The indicators of soil quality were found to have a positive and statistically significant relationship with yield and value of crop output. Households with ownership of medium fertility and high fertility plots were found to have greater yield and value of crop output compared to households owning plots with low soil fertility.

Similarly, institutional services have also significant effect on productivity. While access to extension services has significant effect on productivity, the effect of access to credit is observed on yield per hectare, and not on revenue, which is expected as households may not be able to use improved technology due to credit constraint. Access to improved sanitation is entered to control for the effect of access to basic social services, which is a proxy for health, which has direct effect in improving labor productivity. It has negative sign, implying that lack of basic social services may reduce productivity 
perhaps in reducing labor supply both in farming and marketing activities. Non-farm income was also found to have a positive effect on value of crop output. Both of the region dummies were also found to have a negative relationship with value of crop output. However, the relationship was not found to be statistically significant for yield. Table 1 below presents the results of the estimation.

With regard to the effect of climate variables, the results of the estimation show that both rainfall shock and temperature shock are negatively related with yield per hectare and value of crop output, although at different levels of statistical significance. Households who have experienced a more than one standard deviation change in rainfall in 2013 were found to have smaller yield and value of crop output than those households located in areas with smaller change in rainfall. The same was found to be true for change in temperature. 
Table 1

Productivity Estimates (Inter- annual rainfall)

\begin{tabular}{|c|c|c|}
\hline Variable & Yield in quantity/ha & Value of crop output (Birr) \\
\hline land size in hectare & -0.0045 & $0.0163^{\star \star}$ \\
\hline Male - headed household & 0.5384 & 1.0116 ** \\
\hline Age in years & 0.0040 & -0.0029 \\
\hline Married head & 0.1002 & 0.0083 \\
\hline Household size & $0.1306^{\star *}$ & 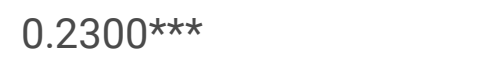 \\
\hline Literacy & -0.2971 & -0.2239 \\
\hline Literacy rate & $1.3430 * \star \star$ & $1.0372^{\star \star}$ \\
\hline No access to improved sanitation & $-0.5867 \star \star$ & $-1.2875^{\star \star \star}$ \\
\hline Access to electricity & -0.0091 & 0.4610 \\
\hline Access to crop extension service & $0.9691^{\star \star *}$ & 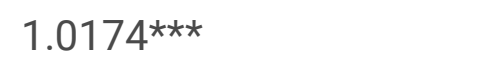 \\
\hline Access to credit & $0.3970^{\star}$ & 0.2398 \\
\hline Access to irrigation & -0.0968 & -0.4932 \\
\hline Fertilizer use & $2.0940 * \star \star$ & $1.7492^{\star \star \star}$ \\
\hline Soil fertility - medium & 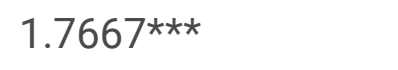 & 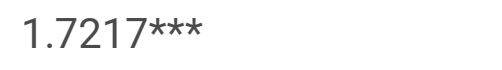 \\
\hline Soil fertility - most fertile & $1.7137 * \star \star$ & 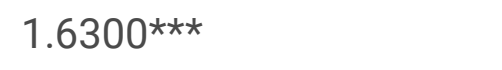 \\
\hline Non - farm income & 0.0859 & 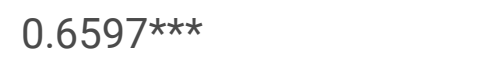 \\
\hline Rainfall shock & $-1.9033^{*}$ & $-2.4721^{\star}$ \\
\hline Temperature shock & 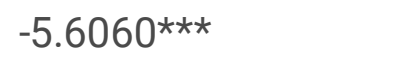 & $-9.3856 * \star \star$ \\
\hline Amhara region & -2.4493 & $-3.4485^{\star}$ \\
\hline Tigray region & -2.1175 & $-2.9040 *$ \\
\hline Constant & $5.5516^{\star \star \star}$ & $8.8144^{\star \star \star}$ \\
\hline $\mathrm{N}$ & 1205 & 1205 \\
\hline r2_a & 0.1511 & 0.2420 \\
\hline Source: Study result & & \\
\hline
\end{tabular}

\subsubsection{Seasonal climate change - productivity model}


Among the ways climate change is reflected is the change in the length and timing of seasons. In countries where traditional agriculture dominates, agricultural production is highly dependent on seasons. Hence, variation in the amount of rainfall and temperature of seasons could strongly affect agricultural productivity. Therefore, it is crucial to explore the effect of the variation in the climate under each season to observe the strength of the impact of climate change on productivity.

Among the seasonal climate shock variables, rainfall shock in Bega season was found to have a negative effect on both yield and crop revenue in sugarcane producing areas. Similarly, temperature shock in Belg was also found to have a negative effect on yield when the total sample is taken under consideration.

Other explanatory variables were also found to have a statistically significant effect on the dependent variables and most of the relationships are maintained in this estimation. Household size is among the household demographic variables that are statistically significant. It was found to have a positive relationship with yield in the total sample and with crop revenue in sugar cane producing areas. Moreover, household literacy rate was found to have a positive relationship with all of the dependent variables. The negative relationship between lack of access to improved sanitation and the productivity indicators is also maintained in these estimations as well.

In addition, access to institutional support such as extension services and credit were found to have a positive relationship with all of the dependent variables under consideration. Similarly, the use of fertilizer was found to have a positive effect on the dependent variables. Furthermore, households with plots of land that have high or medium fertility were found to have higher yield and crop revenue than households owning low fertility plots both for the overall sample and the sugarcane producing areas. Table 2 below shows the effect of seasonal rainfall shocks on the indicators of productivity. 
Table 2

Productivity Estimates (Seasonal Rainfall)

\begin{tabular}{|c|c|c|c|}
\hline Variable & $\begin{array}{l}\text { Yield - total } \\
\text { sample }\end{array}$ & $\begin{array}{l}\text { Yield } \\
\text { sugarcane }\end{array}$ & $\begin{array}{l}\text { Crop Revenue } \\
\text { sugarcane }\end{array}$ \\
\hline land size in hectare & -0.0018 & -0.0003 & 0.0901 \\
\hline $\begin{array}{l}\text { Gender (male - headed } \\
\text { household) }\end{array}$ & 0.6210 & 0.6547 & $1.4619 * \star$ \\
\hline Age in years & 0.0041 & 0.0118 & 0.0038 \\
\hline Married head & 0.0276 & -0.1279 & -0.6265 \\
\hline Family size & $0.1171^{\star *}$ & 0.1125 & $0.1874^{\star \star}$ \\
\hline Literacy rate & $1.1850 \star \star$ & $2.1031^{\star *}$ & $1.5007 \star \star$ \\
\hline No access to improved sanitation & 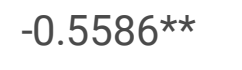 & $-1.1453^{\star *}$ & $-2.3316^{\star \star \star}$ \\
\hline Access to electricity & 0.0456 & 0.1512 & 0.4765 \\
\hline Access to crop extension service & $0.9000 * \star \star$ & $0.8186^{* *}$ & $0.8513^{\star \star}$ \\
\hline Access to credit & $0.4342^{\star}$ & $0.8663^{*}$ & $0.6354^{*}$ \\
\hline Access to irrigation & 0.1169 & -0.1669 & 0.2188 \\
\hline Rainfall shock bega - excess rain & 0.2294 & 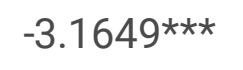 & $-2.6810 * \star \star$ \\
\hline Rainfall shock belg - excess rain & -0.1743 & & \\
\hline Temperature shock - bega & $-2.9448^{\star \star \star}$ & & \\
\hline Fertilizer use & $2.0676^{\star \star \star}$ & 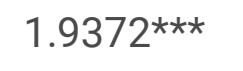 & $1.6562^{\star \star \star}$ \\
\hline Soil fertility - medium & $1.7695^{\star \star \star}$ & $1.9700 * \star \star$ & $1.6144^{\star \star \star}$ \\
\hline Soil fertility - most fertile & $1.6314^{\star \star \star}$ & $2.0766 * \star \star$ & $1.4757^{\star \star \star}$ \\
\hline Non - farm income & 0.0644 & -0.3323 & 0.4127 \\
\hline Cotton growing region & -0.8907 & & \\
\hline Boset - dodota wereda & & $-1.8764^{\star \star \star}$ & 0.2892 \\
\hline constant & $2.5900 * \star \star$ & $3.1082^{\star \star}$ & $2.8770 \star \star$ \\
\hline Sample size & 1205 & 606 & 606 \\
\hline r2_a & 0.1576 & 0.1750 & 0.3138 \\
\hline
\end{tabular}

\subsection{Projected impact of climate change}


This section presents the results of the projected impact of inter-annual and seasonal change in climate on productivity using the model estimated in section 4.1. As it has been explained in the methodological section, the projected impact of climate change is estimated for three scenarios in three periods including short-term, medium-term and long-term periods. As before, we will present the result for inter-annual and seasonal models as follows.

\subsubsection{Impact from Inter-annual climate change model}

Using the estimation results, the study predicts the productivity impact of climate change in the short run (2016-2035), medium run (2046-2065) and in the long run (2081-2100). We considered the result of the climate modelling on the projected change in annual and seasonal rainfall and temperature under different climate change scenarios. Table 3 shows the projected impact of change in inter-annual rainfall on sugarcane yield for the three periods using the three scenarios.

Accordingly, as in the result of the climate modelling which shows that inter annual rainfall does not exhibit a similar trend over the projected period in all the three scenarios, its impact on the productivity of sugarcane also has no clear trend. In short run, while inter-annual rainfall has positive impact on sugarcane productivity under scenario RCP2.6 and RCP8.5, with $0.08 \%$ and $0.20 \%$ increase for each of the respective scenarios, it will likely reduce productivity by about $0.1 \%$ under scenario RCP4.5. On the other hand, the predictions show that under the RCP2.6, there will likely be a $0.10 \%$ reduction in yield in sugarcane in the medium run due to changes in inter annual rainfall. In the long run, it is likely that there will be $0.1 \%$ reduction in yield under the RCP 4.5 scenario due to changes in inter-annual rainfall. Under scenario RCP8.5, change in mean annual rainfall will likely increase productivity by a range of $0.16-0.2 \%$. Overall, the projected inter annual mean rainfall will likely have marginal effect on sugarcane productivity.

Table 3

Inter-annual rainfall change impact projection on yield (Sugar Cane)

\begin{tabular}{|llll|}
\hline Period/Scenario & \multicolumn{3}{l}{ Sugarcane growing region } \\
\cline { 2 - 4 } & RCP2.6 & RCP4.5 & RCP8.5 \\
\hline $2016-2035$ & 0.075 & -0.0980 & 0.1991 \\
\hline $2046-2065$ & -0.0996 & 0.2027 & 0.1576 \\
\hline $2081-2100$ & 0.2893 & -0.0871 & 0.1648 \\
\hline Source: Study result & & \\
\hline
\end{tabular}

A more sever reduction in sugarcane productivity will likely be observed as a result of the change in interannual temperature. The predictions show that the change in inter-annual temperature will cause a reduction in productivity under all scenarios and in both the medium and long run. The reduction ranges from a minimum of $0.30 \%$ in short run under scenario RCP2.6 to a maximum of $1.30 \%$ under RCP8.5 in 
the long run period. In medium term, it is likely that sugarcane productivity will reduce by a minimum of $0.31 \%$ to a maximum of $0.62 \%$. The maximum reductions in sugarcane productivity due to mean annual temperature change will likely result from scenario RCP8.5 (see Table 4). It will likely reduce by $1.3 \%$.

Table 4

Inter- annual temperature change impact projection on yield (Sugar Cane)

\begin{tabular}{|llll|}
\hline Period/Scenario & \multicolumn{3}{l|}{ Sugarcane productivity } \\
\cline { 2 - 4 } & RCP2.6 & RCP4.5 & RCP8.5 \\
\hline $2016-2035$ & -0.2975 & -0.3700 & -0.3120 \\
\hline $2046-1965$ & -0.312 & -0.5442 & -0.6167 \\
\hline $2081-2100$ & -0.3628 & -0.6966 & -1.2987 \\
\hline Source: Study result & & \\
\hline
\end{tabular}

\subsubsection{Impact from seasonal climate change model}

The study also predicted the impact of seasonal climate change on productivity of sugarcane using the econometric model result for seasonal productivity. In the model result, it is only the Bega season that will have significant impact on productivity. Thus, we estimated the magnitude of the impact for this season (Table 5). Accordingly, while the result will have a positive impact on productivity, in the short run under all the three scenarios, the change in rainfall during the Bega season is likely to have a negative effect on productivity under all scenarios in the medium run. The negative effect is, however, the strongest under the RCP2.6 scenario. In the long run, while RCP2.6 and RCP4.5 are likely to have positive impact, Bega season rainfall will likely have negative impact on sugarcane productivity under the RCP8.5 scenario. The positive impact ranges from an increase by $45-129 \%$ in short run whereas the negative impact ranges from a decrease by a margin of $8.5-58 \%$.

Table 5

Seasonal rainfall change impact projection on yield (Bega)

\begin{tabular}{|llll|}
\hline Period/Scenario & \multicolumn{3}{l|}{ Sugarcane growing region } \\
\cline { 2 - 4 } & RCP2.6 & RCP4.5 & RCP8.5 \\
\hline $2016-2035$ & 45.04 & 79.50 & 129.07 \\
\hline $2046-2065$ & -16.62 & -8.46 & -8.16 \\
\hline $2081-2100$ & 46.85 & 50.18 & -58.34 \\
\hline Source: Study result & & \\
\hline
\end{tabular}




\subsection{Projected impact of climate change on crop revenue}

This subsection presents the impact of climate change on annual revenue from crop output in both sugarcane and cotton producing regions.

\subsubsection{Impact from Inter - annual climate change model}

The last three columns of Table 6 presents the impact on revenue from crop output per hectare in cotton producing regions while the impact on revenue from sugarcane is presented in the first three columns. With regards to the effect of climate change on crop revenues in sugarcane producing regions, the change in inter-annual rainfall is predicted to reduce crop revenue under the RCP8.5 and RCP4.5 scenarios in the short run. Revenue will likely to reduce by a range of $0.13-0.26 \%$ for each scenario in short run, respectively. Under scenario RCP2.6, change in inter annual rainfall will likely to increase revenue by about $0.10 \%$ in the same period. In the medium term, the impact is projected to be negative under the RCP2.6 and RCP8.5 scenarios in sugar cane producing areas. In medium period, mean annual rainfall change will likely increase revenue from sugarcane by $0.26 \%$ if scenarioRCP 4.5 is used, otherwise, it will decrease by a range of $0.13-0.20 \%$ under RCP2.6 and RCP 8.5 scenarios. In cotton growing areas, the effect is predicted to be negative for all scenarios in medium term; for RCP2.6 and RCP8.5 for short run and for RCP4.5 in the long run. Maximum positive effect is observed for scenario RCP4.5 during the short run, during which it is likely that mean annual change in rainfall will have about a $0.23 \%$ increase in revenue from sugarcane output. Table 6 shows the predicted impact of inter-annual change in rainfall on crop revenue.

Table 6

Inter-annual rainfall change impact projection on crop revenue

\begin{tabular}{|lllllll|}
\hline Period/scenario & \multicolumn{3}{l}{ Sugarcane growing region } & \multicolumn{3}{c|}{ Cotton growing region } \\
\cline { 2 - 7 } & RCP2.6 & RCP4.5 & RCP8.5 & RCP2.6 & RCP4.5 & RCP8.5 \\
\hline $2016-2035$ & 0.098 & -0.13 & -0.259 & -0.096 & 0.227 & -0.048 \\
\hline $2046-2065$ & -0.129 & 0.264 & -0.205 & -0.143 & -0.099 & -0.002 \\
\hline $2081-2100$ & 0.377 & -0.113 & -0.799 & 0.036 & -0.059 & 0.094 \\
\hline Source: Study result & & & & & \\
\hline
\end{tabular}

Table 7 presents the predicted impact of change in mean annual temperature on crop revenue in both regions. The table shows that there is a substantial reduction in mean annual revenue per hectare due to change in mean annual temperature. The change in temperature is predicted to reduce crop revenue in the medium run under the RCP2.6 and RCP8.5 scenarios in sugarcane growing areas. It is only under scenario RCP4.5 that change in mean annual temperature will have a positive effect in mean annual revenue from sugarcane output. Otherwise, the other two scenarios will result in reducing revenue per 
hectare in all periods. In cotton growing areas, the effect is negative regardless of the climate change scenario under consideration in all study periods.

Table 7

Inter-annual temperature change impact projection on crop revenue

\begin{tabular}{|lllllll|}
\hline Period/ & \multicolumn{2}{l}{ Sugarcane growing region } & \multicolumn{3}{c|}{ Cotton growing region } \\
\cline { 2 - 7 } scenario & RCP2.6 & RCP4.5 & RCP8.5 & RCP2.6 & RCP4.5 & RCP8.5 \\
\hline $2016-2035$ & -0.499 & 0.620 & -0.523 & -0.499 & -0.620 & -0.523 \\
\hline $2046-1965$ & -0.523 & 0.912 & -1.034 & -0.523 & -0.912 & -1.033 \\
\hline $2081-2100$ & -0.608 & 1.168 & -2.177 & -0.608 & -1.167 & -2.177 \\
\hline \multicolumn{2}{l}{ Source: Study result } & & & & & \\
\hline
\end{tabular}

\subsubsection{Impact from seasonal climate change model}

Seasonal changes in mean rainfall will likely also result in an overall negative effect and reduce mean annual revenue from crop output. It is mean Bega season and Belg season rainfall change that will likely have substantial effect on mean annual revenue from crop output in sugarcane and cotton producing regions, respectively. The change in Bega season rainfall is predicted to reduce crop revenue under all scenarios in sugarcane producing areas during the medium run whilst Belg season rainfall will have negative effect in reducing revenue in cotton growing regions in the long run. In the long run, the change in rainfall in the Bega season is predicted to reduce crop revenue under the RCP8.5 scenario in sugarcane growing areas. In cotton growing areas, however, the effect of rainfall change during the Belg season was found to be negative regardless of the type of climate change scenario in the long run. Table 8 presents the predicted values.

Table 8

Seasonal rainfall change impact projection on crop revenue (\%)

\begin{tabular}{|lllllll|}
\hline Period/ & \multicolumn{3}{l}{ Sugarcane growing region } & \multicolumn{2}{l|}{ Cotton growing region } \\
\cline { 2 - 7 } scenario & Bega & & & Belg & \\
& RCP2.6 & RCP4.5 & RCP8.5 & RCP2.6 & RCP4.5 & RCP8.5 \\
\hline $2016-2035$ & 47.72 & 84.23 & 136.75 & -2.84 & 25.36 & -7.72 \\
\hline $2046-2065$ & -17.61 & -8.97 & -8.65 & 8.89 & -34.74 & 1.78 \\
\hline $2081-2100$ & 49.64 & 53.16 & -61.81 & -19.94 & -4.96 & -24.26 \\
\hline Source: Study result & & & & & \\
\hline
\end{tabular}

\section{Conclusions}


The textile and sugar sector are key strategic export commodities in the Ethiopian industrial development strategy. Cotton and sugarcane are key inputs in the production of the two commodities, respectively. Climate change poses risk to the production of these two key inputs and thereby affects the foreign currency earning of the country. Besides, the welfare of households along the value chain of the two commodities is vulnerable to climate change impact. However, the level of the impact varies among the different actors. Impact on the productivity of cotton and sugarcane is one channel through which the impact of climate change translates to welfare of households. Accordingly, in an attempt to analyze the impact of climate change on these two commodities, this study used a cross section data and climate information to estimate the productivity and welfare impact of climate change in cotton and sugarcane producing regions of Ethiopia. The findings are summarized as follow.

The productivity impact analyses revealed that it is likely that climate change will significantly reduce the productivity of sugarcane. In addition, net revenue from sugarcane and cotton will also be reduced due to increase in annual and seasonal temperature as well as change in mean annual and seasonal rainfall. Inter-annual change in rainfall reduces sugar productivity by about $10 \%$ while seasonal change in rainfall reduces productivity by $8-58$ percent in mid-term and long term under RCP8.5. Similarly, interannual rainfall change reduces crop revenue by $20-79 \%$ in sugarcane producing regions while it reduces by at most 0.09 units in cotton producing areas. Seasonal rainfall change reduces crop revenue by 8.65 to 61.8 units in Bega while it reduces by 24.3 units in Belg. On the other hand, change in mean temperature in Bega reduces crop revenue by 0.5 to 2.2 units.

Non-climate drivers of vulnerability will exacerbate the negative impact of climate change. Key non climate drivers of vulnerability include gender, education, institutional support (such as access to extension services, credit, sanitation), technology use and economic (land, access to non - farm income, poverty level) and natural assets (soil, geographical location). These non-climate variables are found to have significant effect on productivity.

To conclude, the projected change in rainfall and temperature from their historical trends indicated that there will be a general decrease in mean annual and seasonal rainfall. In addition, there will also be an increase in mean annual temperature, which also is expected to vary seasonally. While the change in climate will have some positive effect, our result shows that it will likely have an overall significant impact in reducing the productivity of sugarcane and cotton. This reduction in yield and revenue of the two crops will also likely to significantly reduce the welfare of producers. This may also imply that the reduction in the welfare of other actors along the value chain of the two commodities will likely reduce unless effective adaptations mechanisms will be implemented to improve the resilience of these actors. Therefore, it is strongly advisable to identify adaptation options that will minimize the impact and build a climate resilient production of sugarcane and cotton. Finally, we suggest that further study is required to estimate the welfare impact on actors, other than producers, along the value chain of the two commodities.

\section{Declarations}


We declare that this manuscript is original, has not been published before and is not currently being considered for publication elsewhere. As Corresponding Author, I confirm that the manuscript has been read and approved by all the authors.

\section{Competing interests}

The authors declare no competing interests. We know of no conflicts of interest associated with this publication, and there has been no significant financial support for this work that could have influenced its outcome.

\section{Availability of supporting data}

The datasets generated during and/or analyzed during this study are available from the corresponding author on reasonable request.

\section{Funding}

The author(s) received no financial support for the research, authorship, and/or publication of this article.

\section{Acknowledgements}

We would like to acknowledge the technical help, including editorial works, we received from the Ethiopian Development Research Institute.

\section{References}

1. Abera S, Deribe R, Gebreegziabher Z, Kassahun MM, Mekonnen A (2013) "Crop - Livestock InterLinkages and Climate Change Implications for Ethiopia's Agriculture: A Ricardian Approach" Discussion Paper Series, Environment for Development

2. Ahmed SA, Diffenbaugh NS, Hertel T (2009) "Climate Volatility Deepens Poverty Vulnerability in Developing Countries" Environment Research Letters, 4 (2009): 034004

3. Amaliah S, Oktaviani R, Ringler C, Rsegrant MW, Sulser TB (2011) "The Impact of Global Climate Change on the Indonesian Economy" IFPRI Discussion Paper 01148, International Food Policy Research Institute, Washington D.C..

4. Ayinde OE, Ajewole 00, Ogunlade I, Adewumi MO (2010) “Empirical Analysis of Agricultural production and Climate change: a case of Nigeria”, Journal of Sustainable Development in Africa (Volume 12, No.6, 2010)

5. Barrientos S, Khanji N (2002) "Trade Liberalization, Poverty and Livelihoods: Understanding The Linkages", IDS Working Paper 159, Institute of Development Studies, Brighton

6. Cabral L, Ludi E, Peskett L, Stevens C (2007) "Climate Change and Agriculture: Agricultural Trade. Markets and Investment" Overseas Development Institute, London 
7. Cervigni R, Robinson S, Strzepek K (2013) "The Cost of Adapting to Climate Change in Ethiopia: Sector-Wise and Macro-Economic Estimates" ESSP Working Paper 53, Ethiopian Strategic Support Program, Addis Ababa

8. Cerri Carlos Eduardo P, Gerd S, Martial B, Easterling Willian E, Melillo Jerry M, Carlos Clemente C (2007) Tropical Agriculture and Global Warming: Impacts and Mitigation Options. Sci. Agric. (Piracicaba, Braz), v.64, n.l, p.83-99, January/February 2007

9. Cirera X, McCulloch N, Winters A (2001) Trade Liberalization and Poverty: A Hand Book. Center for Economic Policy Research, London

10. Cline WR (2007) " Global Warming and Agriculture. Impact Estimates" Peterson Institute for International Economics, Washington D.C.

11. Deaton A (1989) "Rice Prices and Income Distribution in Thailand: A Non-Parametric Analysis". Econ J 99:1-37

12. Deschenes O, Greenstrone M (2007) "The Economic Impacts of Climate Change: Evidence from Agricultural Output and random Fluctuations in Weather". Am Econ Rev 97(1):355-385

13. Deressa TT (2007) "Measuring the Economic Impact of Climate Change on Ethiopian Agriculture: A Ricardian Approach" Policy Research Working Paper 4342, World Bank, Washington D.C

14. Deschenes Olivier G, Michael (2007) The Economic Impacts Of Climate Change: Evidence from Agriculture Output and Random Fluctuations in Weather. The American Economic Review, Vol. 97, No. 1 (Mar., 2007), pp. 354-385

15. Falco SD, Kohlin G, Ringler C, Yesuf M (2011) " Estimating the Impact of Climate Change on Agriculture in Low-Income Countries: Household Level Evidence from the Nile Basin. Environment Resource Economics, Ethiopia"

16. Gemenne F (2010) "Migration, a Possible Adaptation Strategy?" Syntheses No. 03/10. Institute of Sustainable Development and International Relation

17. IPCC (2014) Climate Change 2014: Impacts, Adaptation, and Vulnerability" Contribution of Working Group II to the Fifth Assessment of intergovernmental Panel on Climate Change. Cambridge University Press, Cambridge, United Kingdom, "Summary for Policy Makers

18. IPCC (2013) Climate Change 2013: The Physical Science Basis" Contribution of Working Group 1 to the Fifth Assessment Report of the Intergovernmental panel on Climate Change. Cambridge University Press, Cambridge, United Kingdom, "Summary for Policy makers

19. IPCC (2000) "IPCC Special Report: Emissions Scenarios", A Special Report of IPCC Working Group III. Intergovernmental Panel on Climate Change

20. Ivanic M, Martin W "Implication of Higher Global Food Prices for Poverty in Low-Income Countries" World Bank Policy Research Working Paper No. 4594, World Bank, Washington D.C

21. John Mary Matovu and Faisal Buyinza (2010) Growth and Household Welfare Effects of Climate Change, Revised Report Submitted for Background Papers for Preparation of the Uganda National Human Development Report 2010, Economic Policy Research Center and Faculty of Economics and Management Makerere University December 2010 
22. Karfakis P, Lipper L, Smulder M (2012) "The Assessment of the Socioeconomic Impacts of Climate Change at Household Level and Policy Implications" in: Building resilience for adaptation to climate change in the agriculture sector, Proceedings of a Joint FAO/OECD Workshop, Rome

23. Kyotalimye M, Mulwa RM, Nelson G, Nzuma JM, Waithaka M (2010) "Strategies for Adapting to Climate Change in Rural Sub-Saharan Africa" IFPRI Discussion Paper 01013, International Food Policy Research Institute, Washington D.C

24. Kurukulasuriya and Robert Mendelsohn (2008) Crop switching as a strategy for adapting to climate change. Bureau of Development Policy, United Nations Development Programme, New York

25. Majule AE, Mary AL (2008) "Impacts of Climate Change, Variability and Adaptation Strategies on Agriculture in Semi-Arid Areas of Tanzania: The Case of Manyoni District in Singida Region, Tanzania". Afr J Environ Sci Technol 3(8):206-218

26. McGuigan C, Reynolds R, Wiedmer D (2002) "Poverty and Climate Change: Assessing Impacts in Developing Countries. and the Initiatives of the International Community"

27. Mendelsohn R, Seo SN (2007) "A Ricardian Analysis of the Impact of Climate Change on South American Farms". Chilean Journal of Agricultural Research 68(1):70-79

28. Olivieri S, Rabassa M, Skoufias E (2012) "The Forecast for Poverty: A Review of the Evidence". In: Skoufias E (ed) The Poverty and Welfare Impacts of Climate Change: Quantifying the Effects, Identifying the Adaptation Strategies. World Bank, Washington D.C., pp 17-51

29. Passel SV, Massetti E, Mendelson R (2012) "A Ricardian Analysis of the Impact of Climate Change on European Agriculture. " Fondazione Eni Enrico Mattei, Italy

30. Ringler C, You GJY (2011) " Climate Change Impacts in Ethiopia: Hydro-Economic Modeling Projections" IFPRI Research Brief 15-19. International Food Policy -Research Institute, Washington D.C.

31. Skoufias E (2012) "Disquiet on the Weather From: Implications of Climate change for Poverty Reduction". In: Skoufias E (ed) The Poverty and Welfare Impacts of Climate Change: Quantifying the Effects, Identifying the Adaptation Strategies. World Bank, Washington D.C., pp 1-15

32. Skoufias E, Katayama RS, Essama-Nssah B (2012) "Too Little Too Late: Welfare Impacts of Rainfall Shock in Rural Indonesia". In: Skoufias E (ed) The Poverty and Welfare Impacts of Climate Change: Quantifying the Effects, Identifying the Adaptation Strategies. World Bank, Washington D.C., pp 5575

33. Skoufias E, Rabassa M, Olivieri S, Brahmbhatt M (2011) "The poverty impacts of climate change" Economic Premise, Poverty Reduction and Economic Management Network (PREM), Number 51. World Bank

34. Temesgen TD, Hassan RM (2009) "Economic Impact of Climate Change on Crop Production in Ethiopia: Evidence from Cross-section Measures", Journal of African economies, Volume 18, Number 4, PP. 529-554 doi:10.1093/jae/ejp002 online date 15 March 2009

35. Tol RSJ (2009) The Economic Effects of Climate Change. Journal of Economic Perspectives 2:2951

Page 27/28 
36. Zhai Fan and Zhuang Juzhong (2009) Agriculture Impact of Climate Change: A General equilibrium Analysis with Special Reference to Southeast Asia. ADBI Working Paper 13. Asian Development Bank Institute 